\title{
"NÃO BATO PONTO PORQUE EU QUERO. NÃO BATO PONTO PORQUE EU GOSTO": CONTROLE SOCIAL E PROSTITUIÇÃO DE TRANSEXUAIS E TRAVESTIS EM CAMPO GRANDE - MS
}

\author{
I DON'T WHORE MYSELF BECAUSE I WANT TO. I DON'T WHORE MYSELF \\ BECAUSE I LIKE IT: SOCIAL CONTROL AND PROSTITUTION OF TRANSSEXUALS \\ AND TRANSVESTITES IN CAMPO GRANDE - MS
}

\author{
"YO NO SOY PROSTITUTA PORQUE QUIERO. YO NO SOY PROSTITUTA PORQUE \\ ME GUSTA": CONTROL SOCIAL Y LA PROSTITUCIÓN DE TRANSEXUALES Y \\ TRAVESTIS EN CAMPO GRANDE - MS
}

\author{
Antonio Henrique Maia Lima ${ }^{1}$ \\ Arlinda Cantero Dorsa ${ }^{2}$ \\ Pedro Pereira Borges ${ }^{3}$
}

\begin{abstract}
RESUMO
O artigo é fruto de reflexões oriundas de pesquisa de campo realizada para uma dissertação de mestrado sobre a marginalização de populações LGBTT na cidade de Campo Grande - MS. A partir das entrevistas surgiu um discurso majoritário justificador do "porque" de maioria dos entrevistados exercerem a prostituição como meio de sobrevivência, apontando para o controle social como o fator-chave para isso, sendo a prostituição a alternativa restante, dados os padrões sociais pré-estabelecidos, nos quais essas pessoas não se consideram ajustados. Tem-se por objetivo analisar criticamente tais fatos a partir das experiências relatadas.
\end{abstract}

Palavras-chave: Travesti. Transexual. Prostituição. Controle Social.

\begin{abstract}
This article is the result of reflections originating from research conducted for a master's thesis about the marginalization of LGBTT people in the city of Campo Grande - MS. From the interviews emerged a justifying major speech "because" the majority of respondents exercise prostitution as means of survival, pointing to the social control as the main factor for this, prostitution arises remaining alternative, given the social standards preestablished in which these people do not consider adjusted. It aims to critically analyze such facts from the experiences reported.
\end{abstract}

Keywords: Transvestite. Transsexual. Prostitution. Social control.

\section{O CAMPO E O TEMPO DA PESQUISA}

A cidade de Campo Grande é a capital do estado de Mato Grosso do Sul. Possui uma população estimada pelo Instituto Brasileiro de Geografia e Estatística (2014) em 843.120

\footnotetext{
${ }^{1}$ Doutorando em Ciências Sociais pela PUC/SP. Docente na Laureate International Education - Anhembi Morumbi de São Paulo-SP. E-mail: henrick_maia@hotmail.com.

${ }^{2}$ Doutora em Língua Portuguesa pela PUC/SP. Coordenadora e Docente do Programa de Pós Graduação em Desenvolvimento Local da UCDB e editora da Revista Interações (UCDB). E-mail: acdorsa@uol.com.br.

${ }^{3}$ Doutor em Ciências Sociais pela PUC/SP. Docente do Programa de Pós Graduação em Desenvolvimento Local - mestrado e doutorado da UCDB e coeditor da Revista Interações da (UCDB). E-mail: pobojar@ucdb.br
} 
habitantes, composta das mais variadas origens, de árabes, japoneses, nordestinos, indígenas de diversas etnias, sulistas, dentre outros. Historicamente a cidade é vocacionada à atração de migrantes de todo o interior do estado, seja em busca de novas oportunidades de vida, seja em busca do curso superior. Com efeito, dentre a população LGBTT do estado de Mato Grosso do Sul esse processo de migração se apresenta corriqueiramente como destino desejável, motivado pela expectativa de "sair do armário" em uma cidade maior, de maiores possibilidades de engajamento social, pertencimento a um grupo de interesses semelhantes e cuja pressão familiar para "dentro do armário" não se faz tão presente ou tão intensa quanto seria em outros contextos, como em uma pequena cidade do interior do pantanal sul-matogrossense, por exemplo. Geralmente essa migração vem embutida no pretexto do curso superior, haja vista que a cidade é uma das poucas do estado que oferece uma boa variedade de cursos e instituições de ensino, mas existem aqueles que migram exclusivamente para fugir da dura realidade de vida que levam em suas cidades de origem. Sobre isso trataremos melhor adiante.

Essas colocações foram possíveis a partir da realização de entrevistas semiestruturadas (ano de 2014) com uma parcela da população de transexuais e travestis da cidade. Tais entrevistas se realizaram para alimentar uma dissertação de mestrado que abordava justamente o desenvolvimento humano e a qualidade de vida da parcela da população composta por travestis e transexuais em um contexto de heteronormatividade, de controle dos corpos e de preceitos sociopolíticos quase que dogmáticos sobre o comportamento sexual humano e os papéis ou performances dos gêneros. A partir desse viés, surgiu ao longo dessas entrevistas uma série de outras discussões que, apesar de não serem o escopo principal da pesquisa à época, não foram desprezadas, sendo analisadas e discutidas posteriormente em artigos científicos independentes como é o caso do presente.

Feitos os esclarecimentos, emergiu, dentre outras, a discussão a partir das entrevistas sobre a razão de a maioria dos entrevistados (cerca $75 \%$ do total) fazer da prostituição seu "ganha-pão", isto é, sua única ou principal forma de subsistência. Sob esse aspecto, verificouse que há certas discordâncias entre as razões apresentadas pelo senso comum, pelo Estado e pela população abordada, a partir de determinados discursos. 


\section{O CONTROLE SOCIAL}

Mannheim (1971, p. 178) define controle social como o "conjunto de métodos pelos quais a sociedade influencia o comportamento humano, tendo em vista manter determinada ordem". Como se viu esse controle se exerce ideológica e discursivamente pela propagação de certos "dogmas" ao longo das gerações. Sociologicamente são os mecanismos empregados pela maioria dominante para estabelecer uma ordem social sob seus próprios preceitos éticos e morais, subvertendo indivíduos a tais padrões e princípios.

Foucault (1999a) denuncia e analisa a invenção de "sexualidades menores" por meio do discurso para os processos sociais de regulação e de normalização. Como salienta Miskolci (2009, p. 154) "os teóricos queer compreendem a sexualidade como um dispositivo histórico do poder", e ainda "sublinham a centralidade dos mecanismos sociais relacionados à operação do binarismo hetero/homossexual para a organização da vida social contemporânea, dando mais atenção crítica a uma política do conhecimento e da diferença”. Nos estudos queer todas as inquietações de Foucault ganham um nome: heteronormatividade:

Um nome que esclarece tanto a que ele direciona à ordem social como seus procedimentos neste sentido. A heteronormatividade expressa as expectativas, as demandas $\mathrm{e}$ as obrigações sociais que derivam do pressuposto da heterossexualidade como natural e, portanto, fundamento da sociedade (MISKOLCI, 2009, p. 156).

A heteronormatividade é uma preocupação constante das instituições (família, igreja, escola, etc.) que se dedicam à ideia de que os seres humanos se dividem em duas categorias distintas e complementares: macho e fêmea, e que cada sexo possui papéis naturais predefinidos na vida. Dessa forma, sexo físico (de nascimento), identidade de gênero e papel social de gênero devem enquadrar todas as pessoas dentro de normas integralmente masculinas ou femininas, consideradas normais. Tudo aquilo que se encontrar fora desse padrão é tido como anormal, doentio, desvio de conduta, sofrendo, consequentemente, inúmeras formas de discriminações (FELIPE, 2012).

Dessa forma, a heteronormatividade se apresenta como um dos maiores mecanismos de controle social exercidos sobre transexuais e travestis, de modo que essa crença na heterossexualidade como característica do ser humano "normal" faz com que qualquer pessoa que saia desse padrão seja considerada fora da norma, o que justificaria sua marginalização (JESUS, 2012). 
Com efeito, o binômio sexo/gênero se apresenta como um gargalo para a efetiva “integração" dessa população ao corpus social campo-grandense. Nessa linha de raciocínio, sociologicamente sexo se refere às diferenças anatômicas e fisiológicas que caracterizam o corpo masculino e o corpo feminino, respectivamente. Gênero, por sua vez, estende-se às diferenças psicológicas, sociais e culturais entre as pessoas de ambos os sexos. O gênero se associa às noções socialmente construídas de masculinidades e/ou feminilidades e não é, necessariamente, um produto intrínseco à biologia do indivíduo (GIDDENS, 2004).

Se o gênero são os significados culturais assumidos pelo corpo sexuado, não se pode dizer que ele decorra de um sexo, desta ou daquela maneira. Levada a seu limite lógico, a distinção sexo/gênero sugere uma descontinuidade radical entre corpos sexuados e gêneros culturalmente construídos. Supondo por um momento a estabilidade do sexo binário, não decorre daí que a construção de "homens" aplique-se exclusivamente a corpos masculinos, ou que o termo "mulheres" interprete somente corpos femininos. Além disso, mesmo que os sexos pareçam não problematicamente binários em sua morfologia e constituição (ao que será questionado), não há razão para supor que os gêneros também devam permanecer em número de dois. A hipótese de um sistema binário dos gêneros encerra implicitamente a crença de uma relação mimética entre gênero e sexo, na qual gênero reflete o sexo ou é por ele restrito (BUTLER, 2003, p. 24).

Ainda de acordo com Butler (2003), o gênero nem sempre é constituído coerentemente ou consistentemente nos diferentes contextos históricos, ele estabelece interseções com modalidades raciais, clássicas, étnicas, sexuais e regionais de identidades discursivamente construídas. O resultado dessa interação é a impossibilidade de separar a noção de gênero das interseções políticas e culturais (relações de poder ou de dominação) em que invariavelmente ela é produzida e mantida. A biologia, a partir deste ponto de vista, não é considerada o “destino" dos seres, já que ninguém é naturalmente homem ou mulher, masculino ou feminino, pois tais adjetivos são resultados de um processo cultural que amolda as identidades de gênero em determinado tempo e espaço (contexto social).

Admitindo-se que o gênero é socializado, isto é, os papéis de gênero são formados a partir da ação de agentes sociais, como a família, a mídia e a escola, tem-se que ele é desenvolvido no indivíduo através de contatos com tais agentes sociais, e por meio de uma progressiva interiorização das normas e expectativas sociais que correspondem ao sexo. As diferenças de gênero são determinadas pela cultura, não pela biologia, razão pela qual existem as desigualdades de gênero, pois homens e mulheres são socializados em papéis diferentes (GIDDENS, 2004). 
Essa concepção binarista (macho ou fêmea, homem ou mulher) se sustenta em linhas tênues, uma vez que, apesar de toda a argumentação do discurso naturalista, o "problema" das minorias de gênero nunca foi solucionado. Em razão disso, historicamente em relação a elas subsiste um discurso autoritário, moralista e religioso de culpabilização, que simultaneamente a) condena a existência da característica diferente, b) atribui ao indivíduo diferente a responsabilidade por ser diferente, c) promove a reprovação do diferente pela totalidade do grupo dominante, mais homogêneo, d) obriga direta ou indiretamente o indivíduo diferente a abrir mão de sua diferença (se possível) para assegurar a manutenção da identidade e do pertencimento ao grupo dominante, e) sugere ao grupo dominante punições ao indivíduo diferente que se negue a ou não possa abrir mão de sua diferença e f) promove a exclusão do indivíduo diferente do grupo dominante.

\section{A EXPERIÊNCIA DAS TRAVESTIS E TRANSEXUAIS DE CAMPO GRANDE - MS}

Aqui serão apresentados os resultados da pesquisa de campo, realizada entre junho e novembro de 2014 em Campo Grande - MS, envolvendo entrevistados voluntários autodenominados transexuais ou travestis, focalizados a partir de indicações de outros voluntários, encontrados em redes sociais, mediante mecanismos de busca ou em eventos voltados ao público LGBTT, em suma, uma espécie de "bola de neve".

O roteiro das entrevistas foi guiado por eixos temáticos com vistas à categorização dos discursos nas seguintes áreas: educação, convívio familiar e social e mercado de trabalho e um último de tema livre, no qual os entrevistados tinham liberdade de falar sobre o assunto que desejassem ou julgassem relevante para o assunto abordado na pesquisa. No eixo livre, as temáticas abordadas foram diversas, porém a mais proeminente foi a prostituição, ou melhor, a justificação por estar na prostituição, do ponto de vista dos entrevistados, evidentemente.

Sobre a educação, na percepção dos entrevistados, o Estado (por meio de seus dirigentes) não permite que as minorias de gênero demonstrem o que são em âmbito escolar, negando-lhes o direito básico de Ser, cuja violação, nos dizeres de Walsh (2010) é profunda infração ao princípio básico da dignidade da pessoa humana, vital para o direito ao desenvolvimento humano.

Para Elizalde, Max-Neef e Hopenhayn (2010) a educação, seja ela formal ou informal, mais que um direito é uma necessidade humana, tal como a alimentação e um abrigo, que se correlaciona com a consciência crítica, a racionalidade, a capacidade de análise e intepretação 
e a autodeterminação, promovendo, segundo Walsh (2010) a potencialidade para o protagonismo de si mesmo e a formação de lideranças na luta pela promoção social de populações marginalizadas.

Essa sensação de negativa por parte do Estado (e da sociedade, por reflexo), é sintoma, segundo Louro (2007) de uma "pedagogia da sexualidade", cuja metodologia legitima até mesmo a violência para a "produção" de meninos e meninas de acordo com a norma cultural pré-estabelecida e convencionada de masculinidade e feminilidade. O propósito dessa pedagogia é produzir homens e mulheres "civilizados", aptos à convivência social coerente e adequada ao contexto social em que se está inserido. Já Foucault (1999a) diria que esses aparatos de poder e força normalizadora típicas da sociedade atual se confundem com a descrição de normas contra as quais lutariam aqueles sujeitos socialmente e discursivamente construídos sob o crivo da normalidade, de modo que se tornariam verdadeiros totens representativos de tudo que não é aceito, não é normal ou não é bem visto.

Foi verificado pelos discursos, uma corrente discursiva onde travestis e transexuais recriminam a si mesmos a partir de uma tomada de consciência sobre seu valor, integridade e (des)ajustamento às normas sociais. Em razão do discurso preconceituoso que enfrentam passam a se esconder, a fingir que não são diferentes, há nesse contexto, o ocultamento da condição diferente para se que as minorias se sintam aceitas em ambiente escolar. Outros discursos, por sua vez, revelam a visão do discurso institucional como uma forma implícita de repressão pessoal, seja pelo ocultamento da condição diferente seja pela visão distorcida de considerar natural, as formas de preconceitos demonstrados pelas piadinhas, pelos deboches e outras formas de bullying por parte dos colegas, havendo um sentimento de desqualificação identitária, de segregação frente aos colegas, de medo da perda do afeto familiar e da ausência total da escola como um apoio a esses desafios enfrentados pelo entrevistado.

Em casos mais agudos há a perda da identidade própria em função de outra, criando-se um personagem que atenda aos padrões impostos e que é identificada pela expressão discursiva "criei essa carapaça", ou seja, um personagem que esteja apto a esconder a transexualidade. É perceptível nessa dinâmica quando os mecanismos de controle social interferiram na personalidade dos entrevistados, pois a carapaça é ao mesmo tempo:

i) uma máscara e um escudo, uma engenhosa estratégia psicológica que possibilita simultaneamente a aceitação, ainda que seja de uma figura que não representa a realidade de 
vida do entrevistado, representado pela expressão discursiva "porque eu me fechei e as pessoas não viam em mim uma criança afeminada".

ii) a possibilidade de proteger o verdadeiro $\mathrm{Eu}$, existente, porém reprimido, escondido, condenado à satisfação por pequenas doses de afeto, que geralmente vêm condicionadas a uma ou outra atitude, representado pela expressão discursiva "até hoje em dia eu não sou (afeminada), eu não tenho trejeitos afeminados".

A escola se torna um ambiente hostil, as instituições falham na manutenção do acesso à educação pelas travestis e transexuais. Há, por consequência, um desdobramento do sentimento da auto-culpa, que somado ao repúdio social à condição transexual provoca uma série de conflitos internos. Verdadeiras patologias que levam ao isolamento e à manutenção do status de excluído ou auto-excluído. $\mathrm{O}$ acesso à educação no contexto de vida das minorias de gênero é institucionalmente assegurado apenas, não havendo maiores sucessos em sua manutenção e concretização, haja vista o despreparo dos exercitadores dos mecanismos de controle.

O índice de evasão escolar nessa parcela da população é alto, este é um dado consolidado e realmente ignorado pelo Estado, havendo pelos meios de comunicação, inclusive, um discurso que culpa essas pessoas por saírem da escola. O fato é que a escola se torna um ambiente hostil às pessoas diferentes ao ponto de que a frequência às aulas se torna insuportável. Do diretor ao professor e aos colegas de turma existem manifestações implícitas e explícitas de preconceito, geralmente negativas, que fazem com que a escola deixe de ser um ambiente de aprendizagem para as minorias de gênero e passe a ser verdadeira câmara de tortura.

O ambiente escolar é intolerante, nesse sentido, aqueles que insistentemente querem permanecer na escola têm de fazer uso de artifícios que possibilitem a ocultação da diferença, pelo uso de diferentes processos de ressignificação da identidade. Há naturalização do preconceito que faz com que a pessoa dê permissão para ser facilmente objeto de descarrego dos controles alheios. Ou ainda mais grave, a vítima do dessas estratégias passa a se enxergar com uma aberração, de fato um erro que deve ser corrigido, iniciando uma guerra psicológica contra a própria natureza. Novamente, Foucault (1999a) sugere que a aceitação da autoridade do outro é o objetivo dos mecanismos de poder, o machismo, a heteronormatividade, o preconceito, etc. são maneiras de amoldar o convívio social às diretrizes de poder dominantes. De modo que, se as pessoas dotadas de autoridade repetem um discurso de reprovação, nada 
mais comum que o próprio reprovado enxergar-se como uma coisa reprovável, internalizando essas manobras discursivas, se culpando, se policiando e se submetendo em busca de uma inclusão.

Essa dinâmica na escola é violenta e, muitas vezes, os próprios funcionários, gestores e professores acabam partilhando do mesmo tipo de conduta. Quem deveria fazer a proteção das pessoas agredidas, acaba sendo, às vezes, o maior agressor. Em Campo Grande - MS, por exemplo, foram registrados casos de estudantes transexuais femininas que solicitaram à direção de suas respectivas escolas permissão para fazerem uso do banheiro feminino. Tal permissão foi negada, e um caso específico se desfechou com um processo judicial e a saída da estudante da escola.

Essa falha na educação de base nega também o acesso ao nível superior por parte das transexuais e travestis entrevistadas. Tal afirmação é plausível, pois do universo de entrevistados menos de um décimo cursa ou cursou o ensino superior, sendo que apenas um terço tem mais de trinta anos de idade, o que revela que a grande maioria se encontra entre os dezoito e trinta anos, faixa etária da maioria dos universitários brasileiros segundo o Censo (2010).

A família como posto no item I também é uma instituição que falha em relação à travestilidade ou transexualidade de um de seus membros. Isso se deve, segundo os entrevistados, a certos juízos de valor formulados sobre sua condição. Diariamente é possível ver discussões desse tipo na mídia, nas quais pessoas com pontos de vista antagônicos se submetem ao debate sobre o que é ser transexual, travesti ou transgênero, por exemplo. São médicos, psicólogos, religiosos, enfim, pessoas que se esquecem de que estão falando de seres humanos, pretensos especialistas que corroboram para a disseminação de um discurso que "exotiza" essas minorias e muito pouco colaboram para a potencialização de seu bem-estar individual e social.

Conforme inquietações de Van Dijk (2000 e 2010) o discurso é uma prática social que reitera as ideias dominantes ao longo do tempo de modo que sistematiza uma ideologia. A aversão às transexuais e travestis é histórica e amplamente difundida nas mais diversas formas de manifestação, das mais camufladas às mais explícitas. Como foi possível perceber nos discursos dos entrevistados, tais manifestações criam um ambiente de medo e insegurança que intervém de forma negativa nas relações sociais e familiares dessas pessoas. O discurso de ódio se encontra arraigado numa cultura primeiramente religiosa, depois individualista e 
heteronormativizada. O papel da religião na propagação de tais pré-julgamentos é fundamental.

A questão do convívio familiar é emblemática nas histórias de vida apresentadas, principalmente no momento de assumir para o mundo as diferenças. $\mathrm{O}$ que se tem por certo é que esse momento é um dos mais importantes da vida de uma pessoa que faz parte do grupo discutido neste trabalho, afinal acarreta seríssimas mudanças físicas, comportamentais, etc. Isto é, uma readaptação de identidade, não só por parte de quem se assume, mas por parte de quem toma conhecimento desse processo

"Sair do armário" é o ápice de uma vida de dúvidas e de sofrimento e, é justamente nesse momento que a família é mais solicitada e, portanto, existe uma grande expectativa em que ela se faça mais presente. $\mathrm{O}$ amparo e o apoio da família são primordiais para que sejam evitados desgastes psicológicos profundos, rompimentos de laços ou outras consequências ainda mais graves, como, por exemplo, o uso de substâncias psicoativas (lícitas e ilícitas), suicídios e homicídios.

Na contramão da necessidade da proximidade da família, têm-se as reações familiares diante da revelação de que um de seus membros possui uma característica diferente. Do universo de discursos sobre a temática, foi possível elencar apenas um cuja família aceitou de pronto a revelação.

Na maioria dos casos, infelizmente, a reação inicial familiar foi negativa, afastando o entrevistado do seu convívio mediante ações de extremo preconceito, como, por exemplo, expulsão de casa, agressão verbal, tentativas diversas de convencimento de que a diferença é apenas uma "fase da vida" ou um erro remediável, fazendo dela um problema de ordem moral, sexual e muitas vezes espiritual. Essas atitudes extrapolam a dimensão pessoal, passando a ser familiar, legitimando assim, uma solução unilateral por parte da família, sem levar em conta, muitas vezes, a vontade do(a) transexual, do(a) travesti ou do(a) intersexual.

Os espaços públicos também não são permissivos em relação às minorias de gênero. $\mathrm{O}$ ônibus, a rua, a praça, enfim, todos os tipos de ambientes de convivência social públicos não se demonstram receptivos, a não ser que exista unicamente para esse propósito. A dinâmica das relações sociais obriga transexuais e travestis a um confinamento em seus próprios espaços, em seus próprios eventos - o gueto, a marginalização. É provável que tal separação não seja consciente, pois acaba sendo mais uma reprodução de um discurso heteronormativizado, como se houvesse duas subespécies diferentes de seres humanos que 
não podem coexistir no mesmo espaço. Os discursos analisados demonstram que em lugares evidentemente "heteros" não são bem vindas as demais variações. Porém, no contrário, em lugares de pessoas diversas, os heteronormativos são bem vindos, pois o próprio ato de se disporem a frequentar tais espaços demonstra que de alguma forma, simpatizam com as diferenças, ou seja, "são amigos".

Para a transexual e a travesti campo-grandense, o fato de sair na rua já é afronta direta à heteronormativização dos espaços públicos, despertando reações de ódio e de preconceito que culminam muitas vezes em explícitas demonstrações de violência verbal e física, que em casos extremados levam até à morte. A figura dessas variações contraria os padrões sociais estabelecidos, agredindo esteticamente inclusive o senso sistematizado do que é "normal", pois quebram o paradigma do "homem de calças e da mulher de vestido".

Abordados foram os entrevistados, também, sobre as perspectivas sobre o mercado de trabalho, como se dão ou como se deram as primeiras tentativas de emprego formal. Diante disso a resposta uníssona foi que a empregabilidade das transexuais e travestis é praticamente inexistente, e quando há, geralmente, ou é para subempregos ou para cargos "típicos" da classe, como, por exemplo, cabelereira e maquiadora. Esse processo evidencia a vulnerabilidade das minorias de gênero frente às expectativas sociais e profissionais, diminuídas em razão das dificuldades enfrentadas. O sentimento de desqualificação, de segregação do convívio laboral propicia o sentimento de marginalidade, muitas vezes imposto pela própria sociedade, levando o entrevistado a buscar na prostituição uma forma de sobrevivência humana.

Essa marginalização tem correlação direta com as temáticas anteriores de análise, tanto em relação à educação e à presença da família na aceitação e acolhimento quanto na vida profissional que se torna o reflexo das problemáticas enfrentadas pelas minorias de gênero no decorrer da vida. O preconceito no mercado de trabalho na mesma medida que a falta de conhecimento e os argumentos usados são os mais diversos possíveis, desde que capazes de justificar o fato daquela pessoa não ser do "perfil" da empresa.

É fato que muitas transexuais e travestis se prostituem em Campo Grande, havendo inclusive regiões da cidade "destinadas" para isso, uma vez que já se tornaram tradicionais redutos de produção dessas pessoas, porém se analisado o Seus respectivos contextos de vida dessas se tornam visíveis as causas desse fenômeno. Fala-se de pessoas que geralmente não tiveram a oportunidade de terminar os estudos, pois pela escola foram negligenciadas. Pessoas 
que muito cedo precisaram ser autossuficientes na vida, sozinhos, pois a família e a sociedade lhes deram as costas. Fala-se de pessoas que não têm ou tiveram a oportunidade de trabalhar.

Diante dessa realidade o (sub)mundo da prostituição parece atrativo, pois é rentável e é um (sub)mundo em que as pessoas vivem escondidos, à margem do palco principal da vida social e, por isso, os pré-conceitos e pré-julgamentos do cotidiano são menos frequentes, o que não significa que não impactam.

As minorias não devem ser associadas a uma inferioridade numérica, mas sim como maiorias silenciosas que, ao se politizar, transformam o gueto e a rua em seus territórios e o estigma em orgulho que se converte em uma identidade, gay, étnica, ou de gênero. A visibilidade que isso provoca tem efeitos duais: por um lado, alguns setores sociais passam a demonstrar aceitação das pluralidades e, até mesmo, a consumir alguns de seus produtos culturais; por outro, setores mais tradicionais ou conservadores renovam seus ataques, realizando desde campanhas de retomadas de valores religiosos e tradicionais da família até manifestações de extrema agressão e violência física promovendo o conflito, no campo das ideias em primeiro plano, e no convívio social quotidiano em segundo plano, reforçando os estigmas e a exclusão (LOURO, 2004).

Nos recortes de entrevistas abaixo exemplificados ${ }^{4}$ foram percebidas muitas inquietações por parte dos entrevistados no que diga respeito à prostituição e ao duplo preconceito por eles sofridos, por serem travestis e transexuais, e por serem prostitutas(os).

D1: Na rua todo mundo olha. Os homens mexem, tem aquelas velhas que até fazem o sinal da cruz. Tem gente que joga pedra, joga lata de cerveja, cospe, uns querem bater. Daí eles esquecem que ali tem uma parte homem também, daí né... a travesti vai se defender, dá uma surra no cara e depois vai pras capas do jornal como se ela que tivesse ido atrás de confusão.

D2: Tem cada tipo de louco nessa vida. Eles param a gente na rua pra fazer as propostas mais absurdas que você imaginar. Eles acham que a gente por ser trans somos obrigadas a fazer e a satisfazer todas as loucuras deles. Dai quando a gente se nega eles começa a tratar a gente mal, como se a gente fosse obrigadas sabe? Não querem pagar, enfim... Tenta empurrar droga na gente. Vire e mexe aparece gente morta nos motéis né? É por causa disso. D3: As travestis da C. e S. têm que fazer sociedade com os carinhas barra pesada, porque lá o negócio é feio. Então elas se juntaram pra se garantir né. Afinal passa um doido por você, te dá um tiro e você nem sabe porque.

D4: Aqui na avenida, pra cima da rotatória eu conheço elas tudinho. O primeiro ponto é da S., o segundo era da D., o terceiro é o da H., mais pra cima, depois do terminal é o da K. Essa eu nem troco muita ideia, porque ela já matou até policial. Tem que ser assim, porque até a polícia, às vezes,

\footnotetext{
${ }^{4}$ Não houve transcriação na análise de dados, tendo sido mantidas todas as expressões proferidas nas entrevistas, no entanto, para preservar a identidades dos envolvidos, todos os nomes próprios e de locais foram reduzidos às respectivas iniciais.
} 
mexe com a gente, só pra dar susto sabe? Como se a gente tivesse ali pra animar as noites deles. Podendo ir atrás de bandido né?. A D. por exemplo, queria muito sair dessa vida, coitada. Ela queria tirar os peitos e voltar a ser homem, porque ela dizia que era muito mais fácil. Coitadinha dela, morreu sem realizar esse sonho. Aquela ali sofreu muito na vida heim... A D. coitada, quantas vezes não apanhou na rua. Lembra do trilho? Então... Uma vez uns caras fingiram que queriam fazer programa e levaram ela pra lá, jogaram ela da moto em movimento. A coitada caiu em cima do trilho e foi para no hospital, com a coxa toda machucada, criou uma bolha de sangue do tamanho de uma bola, teve que drenar, cortar, foi feio. Porrada, ela já levou muita porrada desse povo.

O repúdio social nos discursos acima evidenciados se apresenta de forma explícita e implícita, porém dual em sua natureza. Essa dualidade se dá porque as manifestações de preconceito se intensificam e se edificam sob dois argumentos de reprovabilidade: i) o fato de ser minoria de gênero, e ii) o fato de estar na rua se prostituindo.

Em D1, por exemplo, as manifestações negativas implícitas se apresentam na forma de olhares, ao passo que as manifestações explícitas se mostram de diversas formas, desde o sinal da cruz, que pela fé cristã possui significados também distintos, sendo que pelo principal deles representa um pedido de proteção divina frente a uma agressão à fé, até as agressões físicas. Como manifestação implícita, pode-se exemplificar também, segundo os discursos, o fato das mídias descontextualizarem casos notórios de violência nas ruas envolvendo minorias de gênero, distorcendo as notícias de modo que as travestis, transexuais ou intersexuais sempre sejam os sujeitos causadores de confusão. O que, segundo os discursos, é inverdade, pois na maioria dos casos essas pessoas estão apenas se defendendo das constantes agressões.

No discurso D2 fica evidenciada a ideia de que as minorias de gênero são desqualificadas pelos demais enquanto pessoas humanas. Essa desqualificação fica implícita pelo fato de que os clientes entenderiam que, por serem como são, essas pessoas estariam em uma situação de inferioridade aos demais (às maiorias), o que justificaria uma obrigatoriedade de satisfação de toda e qualquer tipo de fetiche sexual. Nesse processo, a negativa por parte da transexual ou travesti gera sentimentos de revolta e violência, que em muitos casos culminam em morte.

D3, por sua vez, revela as estruturas de poder no (sub)mundo da prostituição campograndense. A violência, sempre próxima, obriga as transexuais e travestis que se prostituem a fazerem alianças com os poderes paralelos não institucionais, por dois motivos: i) alguma forma de proteção, dada a negligência do Estado, e ii) uma forma de pagamento de "aluguel" pelo "ponto de prostituição", uma vez que a rua nesse contexto não é pública, mas 
propriedade privada de determinadas facções. O não pagamento dessa "propina" desencadeia a perda do direito de uso ao "ponto", que geralmente vem acompanhada de uma violenta desapropriação e pela cobrança da dívida pelo uso da força, inclusive com a prestação de serviços forçada, sejam eles sexuais, pela venda de drogas ou como "mulas" do tráfico, atravessando estados e países clandestinamente com pacotes de drogas dentro do corpo ou presos a ele.

O discurso D4 revela outras mazelas desse processo, denunciando um cotidiano desumano e violento que leva, inclusive, à completa negação da natureza transexual ou travesti que gera tentativas de "voltar atrás" nesse processo. Tais tentativas são evidentes formas de buscar uma "normalidade" discursivamente construída, uma fuga, evitando assim, o desgaste diário de se assumir transexual ou travesti.

Outra coisa perceptível nestes e em outros discursos, que por questões de espaços não serão transcritos é que a prostituição, a religião e a necessidade de difundir conhecimentos sobre as diferenças entre travestis e transexuais de outros membros da sigla LGBTT ganham uma projeção mais relevante na mente dos entrevistados do que os próprios assuntos abordados inicialmente. Por exemplo, o adjetivo "prostituta" com conotação pejorativa é muito mais agressivo aos entrevistados do que os adjetivos "traveco" e "desempregado". Isso se deve ao fato de que a maioria dos agressores não tem a sensibilidade de se questionar a razão daquelas pessoas se prostituírem, que é justamente, na maioria dos casos, o fato de não conseguirem emprego e de não terem estudado. A importância simbólica dada à prostituição é de extremo interesse, pois foi nela que se projetou dentre os entrevistados uma grande comoção. Novamente, a necessidade de subsistência obriga essas pessoas a se prostituírem e nesse contexto surge um efeito dominó, um ciclo de causas e consequências que consiste na estruturação social do preconceito para com essas pessoas, tornando-se um verdadeiro ciclo.

Muito embora não seja regra, na maioria dos casos as minorias de gênero sofrem rejeição quando se assumem. As instituições sociais se afastam. A igreja demonstra uma das mais curiosas reações, pois sob um discurso de perdão e inclusão se apresenta como uma espécie de segunda casa para as pessoas, mas quando uma transexual ou travesti a procura como refúgio é aceito somente sob algumas condições, principalmente nas igrejas de vertente evangélica. Essas condições se situam em torno do comprometimento da pessoa em se aproximar de Deus, deixar de lado sua condição diferente e viver como a natureza (Deus) a fez, se redimir do seu "pecado". Trata-se de uma forma clara de se incluir excluindo. 
Da mesma forma que a igreja, o mercado de trabalho também registra suas condições para incluir as minorias de gênero, que geralmente é que ela deixe de ser (ou aparentar ser) transexual ou travesti. Diante disso, a prostituição se apresenta como solução.

Como visto nos discursos, algumas das pessoas que mais condenam as diferenças das minorias de gênero durante o dia são as que as procuram durante a noite para a contratação de serviços sexuais. A prostituição, também vista como pecado, é apenas mais uma das características condenáveis imputadas às travestis e transexuais, porém é a que mais lhes causa revolta, pois a dinâmica do mercado sexual, de transexuais e travestis, sintetiza a hipocrisia da sociedade.

Conforme atestam os discursos, apesar do tamanho, Campo Grande - MS é uma cidade provinciana que propicia contato constante entre os membros de sua população, de modo que, a pessoa que nega emprego à transexual ou travesti é a mesma que paga pelo sexo. O pai que expulsa a jovem transexual de casa é o mesmo que deixa a esposa dormindo sozinha e vai à procura dos serviços sexuais dessas pessoas. O padre ou pastor que as convidam para sua igreja é o mesmo que diz que elas são "coisa do demônio" e que para poderem entrar no templo devem se descaracterizar enquanto pessoa, abrir mão de sua identidade. Certamente esse é o maior dilema das minorias de gênero que se prostituem, pois o ciclo do preconceito está imposto há muito tempo por meio do repetitivo discurso heteronormativo.

Esse ciclo é plausível, pois as instituições alimentam a rejeição às diferenças ao longo das gerações, fazendo do preconceito verdadeira herança. Isso se dá por meio da reprodução do discurso heteronormativo que estrutura e mantém estruturada a hegemonia heteronormativa em um ciclo que precisa ser quebrado.

\section{CONSIDERAÇÕES FINAIS}

Diante da reflexão apresentada, é possível concluir que a heteronormatividade como figura hegemônica se mantém como estruturadora social, posição de onde somente sairá mediante uma reestruturação do pensamento sobre as questões relacionadas à sexualidade humana. Nesse viés, logo se vê a dinâmica hegemônica estabelecida por meio de mecanismo de controle social, manifestados discursivamente e ideologicamente, que buscam a manutenção das instâncias de poder e de controle sociais. À medida que tal estrutura se 
mantém, travestis e transexuais permanecerão como tal e de uma proposição dialética entre preconceito e dominação surgem suas necessidades humanas próprias.

Esta hipótese tem como pressuposto o fato de que a identidade de gênero muitas vezes acaba sendo confundida com orientação sexual dos indivíduos e por serem ambas as concepções "diferentes" do gênero e da sexualidade humana, respectivamente, geralmente sobrepõe-se ao status de cidadão das pessoas. Diante disso, notadamente as transexuais e travestis, por sua condição diferente, certamente possuem necessidades também diferentes dos demais.

Esse contexto de constante reprovabilidade propicia uma auto-culpa, a internalização do preconceito e a tentativa de fuga da realidade de minoria de gênero. Essa fuga é o ápice de um processo ferino que se inicia, como se verificou, no seio da família e passa pela escola, pelo mercado de trabalho, pelas relações sociais, pelo viver em sociedade, acompanhando as fases da vida dessas pessoas.

A reprodução desses mecanismos discursivos e ideológicos contribuem para a manutenção da marginalização. Em alguns casos, em Campo Grande - MS, "quem joga pedra na travesti de manhã é quem paga pelo seu sexo de noite" revelando uma dualidade de pensamento que mostra claramente a força desses mecanismos de controle, afetando o controlador, reprodutor do discurso, assim como os controlados - transexuais e travestis. 


\section{REFERÊNCIAS BIBLIOGRÁFICAS}

BOURDIEU, Pierre. A dominação masculina. Tradução de Maria Helena Kühner. 2. ed. Rio de Janeiro: Bertrand Brasil, 2002.

BRASIL. Ministério do Planejamento, Orçamento e Gestão. Instituto Brasileiro de Geografia e Estatística. Contagem Populacional.

BUTLER, Judith. Problemas de gênero: feminismo e subversão da identidade. Tradução de Renato Aguiar. Rio de Janeiro: Civilização Brasileira, 2003.

CHARAUDEAU, Patrick; MAINGUENEAU, Dominique. Dicionário de análise do discurso. Coordenação e tradução de Fabiana Komesu. 2. ed. São Paulo: Contexto, 2008.

DORSA, Arlinda Cantero. Lingua e Discurso nas crenças culturais sul-pantaneiras. Curitiba: Appris, 2013.

ELIZALDE, Antonio. Desarollo a escala humana: conceptos y experiências. Interações revista internacional de desenvolvimento local. v. 1,n.1, p.51-62. Campo Grande-MS, Set./2000.

La proposta de Desarollo a Escala Humana. In. PNUMA, Programa de las Naciones Unidas para el medio Ambiente. Desarrollo humano y ética para la Sustentabilidad. México/Santiago: PNUMA/Universidade Bolivariana, 2003.

ELIZALDE, Antonio; HOPENHAYN, Martin; MAX-NEEF, Manfred. Desarrollo a escala humana: opciones para el futuro. Madrid: Biblioteca CF+S, 2010.

FELIPE, Jane. Sexualidade na Infância: dilemas da formação docente. In. XAVIER FILHA, Constantina (Org.). Sexualidades, gênero e diferenças na educação das infâncias. Campo Grande, UFMS, 2012.

FOUCAULT, Michel. Arqueologia do Saber. Tradução de Luiz Felipe Baeta Neves. 3 ed. Rio de Janeiro: Forense Universitária, 1987a.

Vigiar e punir: nascimento da prisão. Tradução de Raquel Ramalhete. 27. ed. Petrópolis, Vozes, 1987b.

História da Sexualidade I: a vontade de saber. Tradução de Maria Thereza da Costa Albuquerque e J. A. Guilhon Albuquerque. 13. ed. Rio de Janeiro: Graal, 1999a.

A Ordem do Discurso: aula inaugural no Collége de France. Tradução de Laura Fraga de Almeida Sampaio. 5. ed. São Paulo: Loyola, 1999b.

GIDDENS, Anthony. Sociologia. 4. ed. Tradução de Alexandra Figueiredo. Lisboa: Calouste Gulbenkian, 2004.

JESUS, Jaqueline Gomes de. Orientações sobre identidade de gênero: conceitos e termos. 2. ed. Brasília: 2012. Publicação online, sem tiragem impressa. Disponível em: https://www.sertao.ufg.br/up/16/o/ORIENTA\%C3\%87\%C3\%95ES_POPULA\%C3\%87\%C3\%830_T RANS.pdf?1334065989. Acesso em: 02/09/2014.

LOURO, Guacira Lopes. "Nas redes do conceito de gênero". In: LOPES, M.J.D.; EYER, D.E.; WALDOW, V.R.; (orgs.). Gênero e Saúde. Porto Alegre: Artes Médicas, 1996.

Autêntica, 2004.

O corpo estranho: ensaios sobre sexualidade e teoria queer. Belo Horizonte: 
O corpo educado: pedagogias da sexualidade. Belo Horizonte: Autêntica, 2007.

mai./ago./2008.

Gênero e sexualidade: pedagogias contemporâneas. Pro-Posições. n.2, v.19,

MANNHEIM, Karl. Sociologia Sistemática: uma introdução ao estudo de sociologia. 2.ed. São Paulo: Pioneira, 1971.

MISKOLCI, Richard. A Teoria Queer e a Sociologia: o desafio de uma analítica da normalização. Sociologias. Ano 11. n. 21. Porto Alegre: Jan./jun. 2009, p. 150-182.

PÊCHEUX, Michel. Semântica e discurso: Uma crítica à afirmação do óbvio. Tradução de Eni Pulcinelli Orlandi (et al.). Campinas: Editora da Unicamp, 1997.

VAN DIJK, Teun Adrianus. Analisis crítico del discurso. Conferências de 1994 sintetizadas em E-Book. Disponível em:

http://www.bachillerato.uchile.cl/files/historia/ANALISIS\%20CR\%C3\%8DTICO\%20DEL\%20DISC URSO.doc. Acesso em: set./2014.

Racismo y análisis crítico de los médios. Barcelona: Paidós, 1997.

23-36.

El análisis crítico del discurso. In: Anthropos (Barcelona), 186, set./out. 1999, pp.

El discurso como Interacción en la Sociedade. In. VAN DIJK, Teun Adrianus (Compil.) Discurso como Interacción Social. Barcelona: Gedisa, 2000.

Estructuras e funciones del discurso: una introducción interdisciplinaria a la lingüística del texto y a los estudios del discurso. ed. atual. Barcelona: Siglo XXI, 2005.

Ideología y discurso: una introducción multidisciplinaria. 2. ed. Barcelona: Editorial Ariel, 2008.

Cognição, discurso e interação. 7. ed. São Paulo: Contexto, 2010.

WALSH, Catherine. Desenvolvimento como Buen Vivir: arranjos institucionais e laços (de)coloniais. Novoamerica. 126, abr-jun 2010. 